\title{
Crescimento inicial e biomassa de espécies utilizadas como adubação verde em sistema de aleias
}

\section{Initial growth and biomass of the species used as green fertilization in the alley cropping}

\author{
Bruna Bandeira de Freitas ${ }^{\prime}$; Daniela Pauletto ${ }^{\text {; }}$ Iara Rayana Leal de Sousa ${ }^{1}$ \\ ${ }^{1}$ Universidade Federal do Oeste do Pará, bruna-bandeira@hotmail.com; danielapauletto@hotmail.com; rayana.iaraleal@gmail.com
}

\section{A R T I G O}

Recebido: $13 / 03 / 2019$

Aprovado: 03/11/2019

Palavras-chave:

Gliricidia sepium

Inga heteraphylla

Cultivo em faixas

Key words:

Gliricidia sepium

Inga heteraphylla

Band cultivation

\section{R E S U M O}

Objetivou-se com este trabalho avaliar o crescimento inicial de espécies perenes como gliricídia (Gliricidia sepium) e ingá-xixica (Inga heteraphylla) e o desempenho da produção de biomassa de espécies herbáceas, como a crotalária juncea (Crotalaria juncea L.) e feijão-de-porco (Canavalia ensiformis DC.), utilizadas para adubação verde. O monitoramento do crescimento das espécies foi acompanhado por seis meses. Para avaliar a biomassa, as plantas foram podadas rente ao solo, onde foi obtido o material vegetal total para determinar o peso de massa verde, e retiraram-se quatro amostras de cada parcela para obter o peso da massa seca. $\mathrm{O}$ crescimento em altura final para o ingá-xixica foi de $0,77 \mathrm{~m}$ e de $1,81 \mathrm{~m}$ para a gliricídia. As taxas de crescimento absoluto (TCA) para altura total $(\mathrm{Ht})$ diferem entre ambas as espécies, onde a média da gliricídia apresenta maior valor, de $5,06 \mathrm{~cm} \mathrm{mes}^{-1} \mathrm{em} \mathrm{Ht}$, e a de ingá-xixica é de 2,68 cm mês ${ }^{-1}$. Na avaliação de biomassa total observou-se diferença entre as duas espécies, tanto para massa verde como para a seca, destacando-se o feijão de porco nas duas avaliações com maior produtividade de biomassa fresca de 8,6 $\mathrm{t} \mathrm{ha}^{-1}$ e seca 1,6 $\mathrm{t} \mathrm{ha}^{-1}$. Para indicação no uso como adubação verde, a espécie perene gliricídia, apresentou os melhores parâmetros dendrometricos e, a espécie herbácea feijão de porco, a maior produção de biomassa. \begin{abstract}
A B S T R A C T
The objective of this work was to evaluate the initial growth of perennial species as gliciridia (Gliricidia sepium) and inga-xixica (Inga heteraphylla) and the performance of the biomass production of herbaceous species such as crotalaria juncea (Crotalaria juncea L.) and jack beans (Canavalia ensiformis DC.), used for green manure. Monitoring of species growth was followed for six months. To evaluate the biomass, the plants were pruned close to the soil, where the total plant material was obtained to determine the green mass weight, and four samples were taken from each plot to obtain the dry mass. The final height growth for ingaxixica was $0.77 \mathrm{~m}$ and $1.81 \mathrm{~m}$ for gliricidia. Absolute growth rates (TCA) for total height $(\mathrm{Ht})$ differ between both species, in which the average of gliricidia has the highest value, $5.06 \mathrm{~cm}$ $\mathrm{mes}^{-1}$ in $\mathrm{Ht}$, and that of inga-xixica is $2.68 \mathrm{~cm} \mathrm{mes}^{-1}$. In the total biomass evaluation there was a difference between the two species, both for green and dry mass, with the best jack beans biomass in the two evaluations with the highest fresh biomass productivity of $8.6 \mathrm{tha}^{-1}$ and dry $1.6 \mathrm{t} \mathrm{ha}^{-1}$. For use in green manure, the perennial species gliricidia, which presented the best dendrometric parameters, and the herbaceous species jack beans, with the highest biomass production.
\end{abstract}

\section{INTRODUÇÃO}

A adubação verde é uma prática agrícola que consiste no plantio de espécies vegetais em rotação ou em consórcio com culturas de interesse econômico, podendo ser anuais ou perenes, para cobertura e proteção do solo por determinado período de tempo ou permanente. Além disso, também contribui para manter ou melhorar as condições físicas, químicas e biológicas do solo, proteção da superfície quanto no aporte de fitomassa proveniente da parte aérea e raízes, introdução de microrganismos em profundidade no solo melhorando sua afertilidade e uso eventual da biomassa produzida para alimentação animal ou para outras finalidades (WUTKE et al., 2014 ; SILVA et al., 2014; ESPINDOLA et al., 2005).

$\begin{array}{lc}\text { Revista Verde } & \text { v. } 15, \text { n.1, jan.-mar, p.20-27, } 2020 \\ \text { ISSN 1981-8203 } & \text { doi: } 10.18378 / \text { rvads.v15i1.6458 }\end{array}$


O sistema de cultivo em aleias caracteriza-se pelo manejo de culturas de interesse que são cultivadas nos corredores formados pelas entrelinhas constituídas por plantas adubadeiras de rápido crescimento, arbóreas ou arbustivas (MEIRELLES E SOUZA, 2015). Mattar et al. (2013) e Paulino et al. (2011) relatam que a poda periódica das plantas adubadeiras pode gerar uma ciclagem de nutrientes para o agroecossistema e melhorar as propriedades do solo.

As leguminosas apresentam elevado potencial de fixação biológica de nitrogênio (FBN) e produção de biomassa, portanto, seu uso além de proporcionar economia com fertilizantes, contribui para o manejo ecológico, fundamental para a produção orgânica, estabelecimento e manutenção dos produtores no mercado de forma competitiva e menos dependentes de subsídios (ESPINDOLA et al., 2006). Segundo Wolschick et al. (2016), o uso dessas espécies pode ser considerado uma forma viável de amenizar os impactos da agricultura, trazendo sustentabilidade ao manejo dos solos agrícolas.

A implantação de leguminosas arbustivas e arbóreas ajuda a dinamizar a ciclagem de nutrientes, também colabora na economia de água, na proteção contra pragas e doenças, e no controle da erosão laminar, produzindo pólen e néctar para os inimigos naturais, melhora a estrutura do solo pela adição de matéria orgânica e atividade dos sistemas radiculares dessas plantas, além de auxiliar a redução de infestação por plantas indesejáveis de vegetação espontânea (ALVES et al., 2004).

Destacam-se como espécies promissoras para a prática da adubação verde as espécies avaliadas no presente estudo: as perenes gliricídia (Gliricidia sepium (Jacq.) Steud.) e ingá-xixica (Inga heteraphylla Willd.) e as herbáceas crotalária juncea (Crotalaria juncea L.) e feijão-de-porco (Canavalia ensiformis DC.), por serem plantas rústicas, de rápido crescimento, adaptadas a condições de baixa fertilidade e elevadas temperaturas (AGUIAR JÚNIOR et al., 2011; XISTO, 2009). Diante do exposto, o objetivo com este trabalho foi avaliar o crescimento inicial de espécies perenes e o desempenho da produção de biomassa de espécies herbáceas utilizadas para adubação verde, visando uma proposta de alternativa de adubação verde para a região.

\section{MATERIAL E MÉTODOS}

$\mathrm{O}$ experimento foi desenvolvido em uma área localizada na Fazenda Experimental da Universidade Federal do Oeste do Pará - UFOPA, localizada às margens da rodovia PA 370 (Curuáuna), no município de Santarém, estado do Pará. A altitude média de 35 metros, a classificação climática da região é Am- Clima tropical úmido ou subúmido (classificação Koppen), sendo quente e úmida, com variação de temperatura média anual na faixa de 25 a $28{ }^{\circ} \mathrm{C}$, umidade relativa média do ar de $86 \%$ e precipitação média anual é de $1920 \mathrm{~mm}$, sendo que a maior intensidade ocorre de dezembro a maio, quando a precipitação mensal varia de 170 a $300 \mathrm{~mm}^{\text {mês }}{ }^{-1}$ (FERREIRA, 2011). Os dados de precipitação utilizados neste trabalho, no período de agosto de 2017 a março de 2018, foram obtidos por meio de pluviômetro em plástico rígido, instalado na fazenda experimental, com escala de 0 a $130 \mathrm{~mm}$ e monitoramento diário.

Os solos no município são do tipo Latossolo Amarelo de textura média, argilosa a muito argilosa de textura indiscriminada (IDESP, 2014). Em grande parte da fazenda experimental, houve atividades voltadas para a pecuária, principalmente criação de animais bovinos, e, posteriormente, a área ficou em pousio por cerca de 10 anos antes da implantação do experimento deste estudo.

$\mathrm{O}$ experimento com espécies perenes foi instalado em fevereiro de 2017 com o plantio das mudas de ingá-xixica (Inga heteraphylla Willd.) e gliricídia (Gliricidia sepium (Jacq.) Walp.), e foram divididas quatro faixas com as espécies, sendo duas faixas alternadas de cada espécie (Figura 1). O ingá-xixica foi plantado por meio de mudas feitas com sementes, e a gliricídia com mudas oriundas de estacas com introdução de 10 $\mathrm{cm}$ no solo, ambas produzidas no viveiro da Universidade Federal do Oeste do Pará-UFOPA e levadas a campo quando atingiram altura superior a $50 \mathrm{~cm}$ e inseridas ao solo para que fossem enraizadas. O plantio foi realizado em fileiras simples com espaçamento de $2 \mathrm{~m}$ entre as plantas e $6 \mathrm{~m}$ entre fileiras, totalizando 20 exemplares de cada espécie.

$\mathrm{O}$ experimento com espécies de ciclo curto foi desenvolvido nas entrelinhas do plantio de espécies perenes (ingá-xixica e gliricídia). A limpeza da área, que continha vegetação secundária, foi realizada pelo corte raso e queima controlada dos resíduos vegetais (setembro e outubro de 2016), visto que essa condição de manejo ainda é a realidade que domina na região. Para a implantação do experimento, realizado em novembro de 2017, foram realizados tratos culturais como limpeza manual e roçagem semi-mecanizada entre as quatro linhas de plantio. Em seguida procedeu-se a aplicação de 2,5 t.ha${ }^{1} \mathrm{~kg}$ de calcário dolomítico nessas entrelinhas, estabelecendo um período de 48 dias, tempo aproximado necessário para o calcário corrigir a acidez no solo, segundo Cravo et al. (2010).

Em janeiro de 2018, foram coletadas 10 amostras de solo de 0-20 $\mathrm{cm}$ de profundidade com o auxílio de um trado, para verificação das características químicas do solo após a aplicação do calcário (Tabela 1). Em seguida, foram incorporados ao 180 $\mathrm{kg}$ de esterco bovino curtido, sendo um em cada linha das espécies perenes já implantadas, para auxiliar no desenvolvimento das plantas adubadeiras e a queima realizada anteriormente se justifica por ser tipicamente comum na região, sendo as espécies adubadeiras alternativas a essa prática.

Tabela 1. Características químicas do solo $(0-20 \mathrm{~cm})$ no local de estudo na Fazenda Experimental da Ufopa, Santarém-Pará.

\begin{tabular}{|c|c|c|c|c|c|c|c|c|c|c|c|c|c|}
\hline MO & $\mathrm{N}$ & $\mathrm{P}$ & K & $\mathrm{Na}$ & $\mathrm{Al}$ & $\mathrm{Ca}$ & $\mathrm{Ca}+\mathrm{Mg}$ & $\mathrm{pH}$ & $\mathrm{H}+\mathrm{Al}$ & & TC & \multicolumn{2}{|c|}{ Saturação } \\
\hline $\mathrm{g} / \mathrm{kg}$ & $(\%)$ & & $\mathrm{mg} / \mathrm{dm}^{3}$ & & \multicolumn{3}{|c|}{$\mathrm{cmol}_{\mathrm{c}} / \mathrm{dm}^{3}$} & Água & $\mathrm{cmolc} / \mathrm{dm}^{3}$ & Total & Efetiva & Base & Alumínio \\
\hline & & & & & & & & & & \multicolumn{2}{|c|}{$\mathrm{cmol}_{\mathrm{c}} / \mathrm{dm}^{3}$} & V\% & $\mathrm{m} \%$ \\
\hline 21,9 & 0,09 & 4 & 18 & 11 & 0,8 & 0,6 & 1,0 & 4,50 & 4,58 & 5,56 & 1,87 & 19,26 & 41,6 \\
\hline
\end{tabular}


Após aplicação de esterco, foram plantadas as sementes de feijão de porco (Canavalia ensiformes) e crotalária (Crotalaria juncea) nas entre linhas do ingá-xixica e gliricídia, semeadas manualmente em cova, onde foram inseridas três sementes de cada espécie, aos 15 dias após a germinação, foi realizado o desbaste, deixando-se a planta mais vigorosa. Desta maneira, foram semeadas em 7 linhas espaçadas com $50 \mathrm{~cm}$ entre cada cova, em parcelas de $6 \times 4 \mathrm{~m}$, resultando em densidade de 3,5 plantas $\mathrm{m}^{-2}$ (Figura 1). As plantas foram cortadas 60 dias após o plantio.

Figura 1. Croqui representativo dos experimentos com as espécies ingá-xixica, gliricídia, feijão-de-porco e crotalária na Fazenda Experimental da Ufopa, Santarém, Pará.

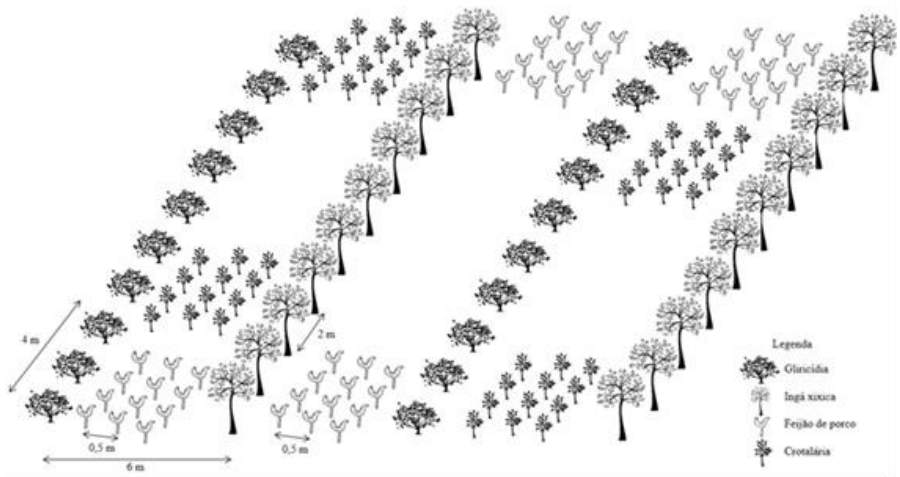

Para o monitoramento do crescimento das espécies, os indivíduos foram numerados através de placas de identificação e mensurados a partir do sexto mês de implantação em campo até os 11 meses de idade. Para o monitoramento, utilizaram-se medidas de dimensões lineares com mensuração mensal das variáveis: altura total (Ht) e diâmetro a altura do colo (DAC), utilizando trenas e paquímetro digital com gliricídia medindo DAC inicial de $18,62 \mathrm{~cm}$ e ingá-xixica $8,95 \mathrm{~cm}$.

A partir das variáveis coletadas para a análise do crescimento de ingá-xixica e gliricídia, foram determinadas as taxas de crescimento absoluto (TCA) e de crescimento relativo (TCR) para os parâmetros Ht e DAC, conforme metodologia de Benincasa (2004), de acordo com as Eqs. (1) e (2).

$$
T C A=(M 2-M 1) /(T 2-T 1)
$$

Em que: TCA- Taxa de crescimento absoluto; M2- Medição final da altura ou diâmetro; M1 - Medição inicial da altura ou diâmetro; T2- Tempo final e T1- Tempo inicial.

$$
\mathrm{TCR}=(\ln \mathrm{M} 2-\ln \mathrm{M} 1) /\left(\mathrm{T}_{2}-\mathrm{T}_{1}\right)
$$

Em que: M2- medição final da altura ou diâmetro; M1- medição inicial da altura ou diâmetro; T2- T1 = intervalo de tempo; ln logarítmo neperiano.

Optou-se pelo uso da TCA, pois esta expressa o crescimento da planta em um intervalo de tempo em relação à variável acumulada no início desse intervalo (MACHADO et al., 2006). A TCA é indicada para avaliar a velocidade média de crescimento ao longo do período de observação (BENINCASA, 2004).
Para as variáveis Ht e DAC, utilizaram-se o Incremento Médio Mensal (IMM) e Incremento Absoluto (IA) submetidos ao teste $\mathrm{T}$ de Student não-pareado, ao nível de $95 \%$ de probabilidade. As análises foram realizadas através do software Biostat.

Para avaliação do grau de dispersão e associação linear entre duas variáveis, calculou-se o coeficiente de correlação de Person (r), adotando-se a escala estabelecida por Dancey e Reidy (2006), em que $r=0,10$ até 0,30 indica correlação fraca, $r=0,40$ até 0,60 corresponde à correlação moderada e $r=0,70$ até 1 significa correlação forte.

Para a avaliação da biomassa, as plantas foram cortadas rente ao solo aos 60 dias. O material vegetal total de cada parcela foi pesado a fim de se determinar o peso de massa verde. E com o objetivo de determinar a massa seca, após a pesagem da massa verde, retiraram-se quatro amostras de cada espécie por parcela, sendo que cada amostra continha quatro plantas escolhidas aleatoriamente. As amostras coletadas foram acondicionadas em sacos de papel e colocadas em estufa de ventilação forçada a 65 ${ }^{\circ} \mathrm{C}$, até atingir peso constante. Posteriormente, o material restante de massa verde foi distribuído de forma uniforme na superfície sobre cada parcela em campo.

Foi realizada a média das amostras das parcelas. Os dados foram analisados estatisticamente por meio de médias comparadas pelo teste $\mathrm{T}$ de Student pareado a $5 \%$, usando o software BioEstat 5.3.

A porcentagem de sobrevivência das mudas foi avaliada com base no número de mudas no início e ao final no experimento.

\section{RESULTADOS E DISCUSSÃO}

A sobrevivência do ingá-xixica foi de $95 \%$, enquanto o percentual de sobrevivência que a gliricídia apresentou foi de 75\%. Miranda e Valentim (2000) observaram valores superiores com um percentual de $95 \%$ de sobrevivência aos 12 meses de idade para a espécie de Gliricidia Sepium plantadas em sistema de mudas. Em plantios de espécies perenes, entre elas o gênero Inga e Gliricidia em sistemas agroflorestais. Costa et al. (2009) relataram $78 \%$ sobrevivência em estudo realizado no estado do Amazonas. Silva e Corrêa (2008) também encontraram resultados parecidos, com $77,8 \%$ para espécies arbóreas no Distrito Federal, enquanto que Almeida e Sánchez (2005) consideram mortalidade de $10 \%$ de mudas como referência em projetos de reflorestamento, valor este aproximado à média de mortalidade da espécie ingá-xixica neste estudo. $\mathrm{O}$ pH ácido do solo da área experimental pode ser um dos fatores que afetaram a sobrevivência da gliricídia, que foi a espécie com menor porcentagem de sobrevivência, embora Drumond e Carvalho Filho (1999) tenham informado que a espécie se desenvolva em diversos tipos de solos e tenha alta resistência à seca, baseados em estudos no semiárido brasileiro.

Em estudo realizado por Costa et al. (2009), os adubos verdes (Gliricidia sepium e Inga edulis) se destacaram como importantes fontes de $\mathrm{N}, \mathrm{K}$ e $\mathrm{Ca}$, e a adição frequente desses adubos verdes se mostrou como fonte de P. Os atributos relacionados à fertilidade do solo $\mathrm{P}, \mathrm{K}$ e $\mathrm{Ca}+\mathrm{Mg}$ apresentam valores de $4 \mathrm{mg} \mathrm{dm}^{-3}, 18 \mathrm{mg} \mathrm{dm}^{-3}$ e 1,0 cmolc $\mathrm{dm}^{-3}$ 
respectivamente, valores estes que encontram-se na classe de teores baixos baseado recomendações de adubação e calagem para o estado do Pará (CRAVO et al., 2010).

$\mathrm{Na}$ Figura 2, estão representadas as médias das alturas das espécies de ingá-xixica e gliricídia no decorrer dos seis meses de acompanhamento, em que as duas espécies apresentaram crescimento contínuo em altura total $(\mathrm{Ht})$.

Figura 2. Altura total média (m) e desvio padrão das espécies ingá-xixica e gliricídia em Santarém, Pará.

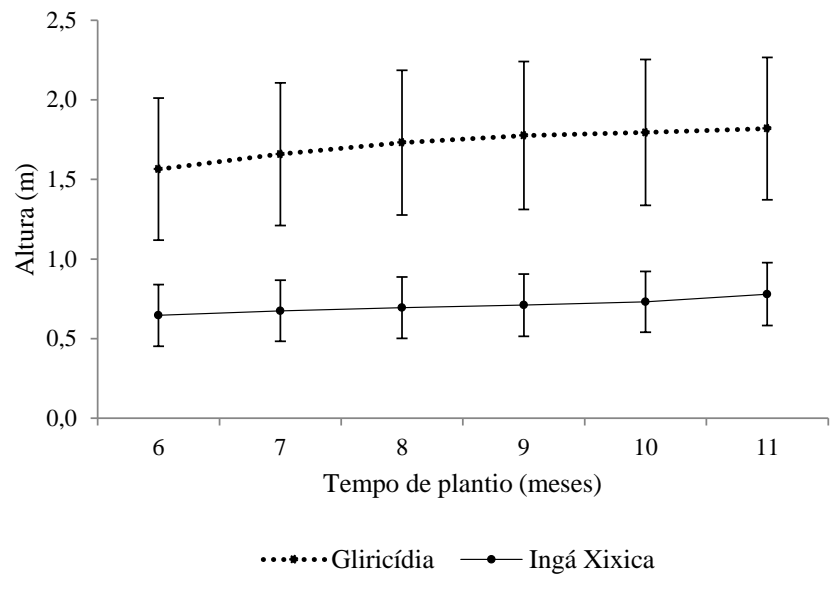

O ingá-xixica apresentou um leve acréscimo (7\%) na altura no mês 11 , fator este que pode ser reflexo do início do período chuvoso, durante o mês de dezembro de 2017, com precipitação de $157 \mathrm{~mm}$ e $262 \mathrm{~mm}$ em janeiro de 2018, valores superiores aos meses anteriores (agosto a novembro) com precipitação acumulada de $57 \mathrm{~mm}$. As médias de crescimento em altura, aos 11 meses, para o ingá-xixica foram de $0,77 \mathrm{~m}$ e $1,81 \mathrm{~m}$ para a gliricídia. Melo et al. (2015) constataram crescimento de gliricídia de 0,18 m, aos dois meses. Em estudo com Inga marginata, realizado por Nascimento et al. (2012), são descritos resultados de $1,5 \mathrm{~m}$ de altura com espaçamento de $2 \mathrm{~m}$ entre as plantas aos 22 meses, dobro de tempo deste experimento. $\mathrm{Na}$ idade de início das medições (seis meses), a gliricídia apresentou DAC com valor médio de $2,03 \mathrm{~cm}$ para mudas produzidas a partir de estacas (Figura 3). Este resultado pode ser considerado satisfatório quando comparado aos encontrados por Silva (2009), quando mostram que esta espécie, aos três meses de idade, em experimento realizado com sementes, apresentou diâmetro de $0,72 \mathrm{~cm}$. Já no cultivo em viveiro na Paraíba foi relatado aos 100 dias um diâmetro de 0,62 $\mathrm{cm}$ por Cavalcante et al. (2016)

O ingá-xixica apresentou $1,2 \mathrm{~cm}$ de DAC aos 11 meses de acompanhamento (Figura 3), enquanto Nascimento et al. (2012) constataram 3,9 cm de DAC em cultivo aos 22 meses de idade para a espécie do mesmo gênero Inga marginata.

Constatou-se diferença significativa entre as médias de DAC das duas espécies avaliadas ao nível de 95\% de confiabilidade, sendo que as médias da gliricídia apresentaram maiores valores, de $2,03 \mathrm{~cm}$ no primeiro mês e $2,60 \mathrm{~cm}$ no último mês, enquanto o ingá-xixica variou de 1,01 a $1,24 \mathrm{~cm}$ no primeiro e último mês, respectivamente.

Figura 3. Diâmetro a altura do colo (DAC) e desvio padrão das espécies ingá-xixica e gliricídia em Santarém, Pará.

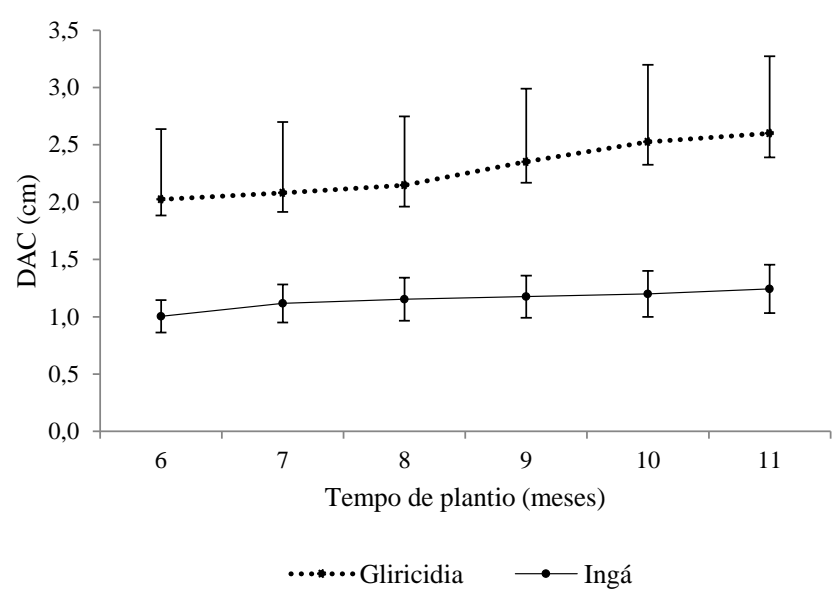

As taxas de crescimento absoluto (TCA) para Ht diferem entre ambas as espécies em que a média de gliricídia apresenta maior valor $\left(5,06 \mathrm{~cm} \mathrm{mes}^{-1} \mathrm{em} \mathrm{Ht}\right)$ que o ingá-xixica $(2,68 \mathrm{~cm}$ mês $^{-1}$ (Tabela 2). A TCA para a variável DAC apresentou diferença estatística em que a gliricídia destacou-se com maiores valores $\left(1,15 \mathrm{~mm}\right.$ mês $\left.{ }^{-1}\right)$ que o ingá-xixica $\left(0,48 \mathrm{~mm}\right.$ mês $\left.\mathrm{s}^{-1}\right)$.

Tabela 2. Taxa de crescimento absoluto (TCA) e taxa de crescimento relativo (TCR) em altura total (HT) e diâmetro a altura do colo (DAC) para as espécies ingá-xixica e gliricídia.

\begin{tabular}{ccccc}
\hline & Ingá-xixica & Gliricídia & Valor- $p$ \\
\hline HT (cm/mês & \multicolumn{3}{c}{ TCA } & \\
DAC & 2,68 & & 5,06 & 0,023 \\
& 0,48 & & 1,15 & 0,015 \\
HT & 0.04 & TCR & \\
DAC & 0,04 & & 0.03 & 0.307 \\
\hline
\end{tabular}

Para a taxa de crescimento relativo (TCR) da variável $\mathrm{Ht}$, as diferenças não foram significativas com média de 0,04 e 0,03 $\mathrm{cm}$ mês $^{-1}$ para ingá-xixica e gliricídia, respectivamente.

Conceitualmente a taxa de crescimento de uma planta é uma função do tamanho inicial (BENINCASA, 2004), e por este motivo a TCR é apontada como o índice mais indicado para avaliar crescimento inicial de plantas na mesma espécie (LIMA et al., 2007). As variações na TCR podem ser decorrentes das diferenças genéticas entre espécies e variedades, do estágio de desenvolvimento da planta, das condições climáticas e do manejo empregado (OLIVEIRA et al., 2000). Considerando este índice, verificou-se que as duas espécies em análise tiveram o mesmo comportamento, visto que não houve diferença estatística, indicando que a alocação de material foi proporcional ao tamanho inicial para as duas espécies. Porém, considerando a produção de biomassa para uso como adubação verde, percebese que a TCA se mostrou mais representativa do que a TCR, por demonstrar mais claramente os ganhos em crescimento inicial ao longo do tempo, pois, conforme exposto por Carvalho et al. (1999), um dos principais parâmetros utilizados na avaliação dos adubos verdes é a produção de biomassa aérea, pois reflete o potencial de extração e ciclagem de nutrientes.

O uso de espécies de apoio em sistema de cultivo em aleias pressupõe que a espécie perene cultivada entre as de ciclo curto 
tenha uma rápida produção de biomassa para que seja possível realizar podas periódicas e assim acrescentar material vegetal ao solo e favorecer os cultivos de interesse econômico (MARIN et al., 2007; QUEIROZ et al., 2007). Assim, índices como a TCR, que consideram somente o crescimento proporcional ao tamanho inicial, apontam que o ingá-xixica apresentou o mesmo crescimento que a gliricídia, não refletindo o desenvolvimento em campo, visto que a gliricídia foi à espécie que mais se desenvolveu em Ht com Incremento Médio Mensal (IMM) de 5,1 cm comparado a 2,7 cm para o ingá-xixica (Tabela 3). Sousa et al. (2007), em estudo realizado no Amazonas, constataram que o ingá-xixica apresentou menor tolerância a podas drásticas enquanto a gliricídia se adapta melhor a esse manejo.

Tabela 3. Incremento Médio Mensal (IMM) e Incremento Absoluto (IA) em altura total para duas espécies (Ingá-xixica e gliricídia) em Santarém, Pará.

\begin{tabular}{cccc}
\hline & Igá-Xixica & Gliricídia & Valor $P$ \\
\hline IMM (CM) & 2,7 & 5,1 & 0,0252 \\
IA (CM) & 13,6 & 25,3 & 0,0252 \\
\hline
\end{tabular}

A espécie que mais se destacou em crescimento absoluto para diâmetro foi a gliricídia com $5,7 \mathrm{~mm}$ de incremento, enquanto o ingá apresentou 2,4 $\mathrm{mm}$ (Tabela 4). Os valores para a primeira espécie representam $1 / 4$ do valor encontrado por Miranda e Valentim (2000), que observaram um incremento de 19,7 mm em acompanhamento da mesma espécie por 4 anos no estado do Acre. Melo et al. (2015) constataram um DAC de 6,6 mm para avaliação de crescimento de gliricídia aos dois meses.

Tabela 4. Incremento Médio Mensal (IMM) e Incremento Absoluto (IA) em DAC para duas espécies em Santarém, Pará.

\begin{tabular}{|c|c|c|c|}
\hline & INGÁ- & GLIRIC & VAL \\
\hline IMM & 0,5 & 1,1 & 0,015 \\
\hline IA & 2,4 & 5,7 & 0,015 \\
\hline
\end{tabular}

A diferença entre o IA $(3,3 \mathrm{~mm})$ para diâmetro nas duas espécies demostra que o crescimento inicial destas espécies se mostrou distinto. Um fator atrelado a este resultado pode estar ligado à parte aérea da planta, pois as duas espécies avaliadas apresentam comportamento distinto. A gliricídia tem crescimento cespitoso, formando em média quatro a cinco fustes (AGUIAR JÚNIOR et al., 2011), além de apresentar alta capacidade de regeneração e resistência à seca (DRUMOND; CARVALHO FILHO, 1999). Já o ingá-xixica demonstrou uma incipiente ramificação e crescimento da copa com notável dimensão inferior ao da gliricídia. Neste sentido, monitorar outras variáveis como diâmetro da parte aérea ou quantidade de ramos poderia ofertar mais parâmetros para comparação das espécies.

O desenvolvimento da parte aérea e formação de copa se apresentam de forma imprescindível para espécies utilizadas para adubação verde, o que indicou que a gliricídia tem a maior potencialidade, pois aos 11 meses de idade já apresentava ramificação suficiente para execução de podas, enquanto que o ingá-xixica ainda detinha aspecto de muda.
O manejo do sistema de aleias é feito por meio de podas da parte aérea das leguminosas durante a estação de crescimento da cultura principal, e o produto dessas podas é aplicado no solo, onde se decompõe e fornece nutrientes às plantas (EIRAS; COELHO, 2011). O número de cortes realizados por ano depende da velocidade de rebrota das leguminosas após cada corte e da adequação às características das espécies semeadas nas entrelinhas. A semeadura nas entrelinhas ocorre no início das chuvas, desta forma, é feita uma poda drástica da leguminosa para retardar a rebrota e recomposição da copa e, com isto, atenuar seu efeito competitivo (BARRETO; CARVALHO FILHO, 1992).

Espera-se que, com a incorporação periódica de quantidades expressivas de biomassa das leguminosas nas entrelinhas, obtenham-se melhorias nas características químicas, físicas e biológicas dos solos, com consequente aumento do seu potencial produtivo (SILVA; MENDONÇA, 1995). Logo, no presente estudo, a gliricídia se destaca nesse quesito, pois apresentou um crescimento mais expressivo que o ingá-xixica. Eiras e Coelho (2011) ainda relatam que a poda para espécies perenes deve ser realizada na estação chuvosa, para que as árvores tenham rápida reposição das suas folhas, pois, se ocorrer no final das chuvas, as copas permanecem bastante reduzidas durante a estação seca, com menor capacidade de sombreamento.

A Tabela 5 apresenta as principais correlações verificadas para variáveis dendrométrias e pluviométricas. O efeito da precipitação mensal sobre a Ht do ingá-xixica $(r=0,39)$ obteve um resultado de correlação fraca, enquanto para a mesma variável dendrométrica quanto ao número de dias com chuva a correlação foi considerada moderada $(r=0,42)$, demostrando que as variáveis pluviométricas não expressaram influência relevante sobre o crescimento desta espécie. Embora Farias et al. (2009) demonstrem que a espécie perene gliricídia se desenvolva melhor em períodos chuvosos, Carvalho Filho et al. (1997) afirmam que a mesma espécie é uma leguminosa arbórea que apresenta crescimento rápido e enraizamento profundo, o que lhe confere tolerância à seca.

Tabela 5. Correlação entre precipitação mensal (mm) e número de dias com chuva com diâmetro a altura do colo (DAC) e altura total $(\mathrm{Ht})$ das espécies estudadas.

\begin{tabular}{ccc}
\hline & \multicolumn{2}{c}{ VARIÁVEIS } \\
VARIÁVEIS & \multicolumn{2}{c}{ PLUVIOMÉTRICAS } \\
\cline { 2 - 3 } DENDROMÉTRICAS & $\begin{array}{c}\text { Precipita } \\
\text { ção } \\
\text { mensal }\end{array}$ & $\begin{array}{c}\text { Número de dias } \\
\text { com chuva }\end{array}$ \\
\hline HT & 0,39 & Ingá-xixica \\
DAC & 0,07 & 0,42 \\
HT & & 0,12 \\
DAC & $-0,01$ & 0,04 \\
\hline
\end{tabular}

Para o diâmetro do ingá-xixica e gliricídia, a influência do número de dias e precipitação foi menos perceptível, pois identificou-se baixa correlação referente ao diâmetro, sendo que desta forma é inviável se estimar ou prever futuros 
comportamentos que envolvam tais características conjuntamente.

$\mathrm{Na}$ avaliação de biomassa total das espécies observou-se diferença estatística entre as duas espécies, tanto para massa verde quanto para massa seca, se destacando o feijão-de-porco nas duas avaliações. O feijão-de-porco teve o percentual de sobrevivência de $98 \%$, enquanto a crotalária apresentou apenas $45 \%$.

A produtividade de biomassa fresca e seca das espécies estudadas separadamente foi baixa (Tabelas 5), quando comparadas com informações existentes na literatura, que apontam valores mais elevados, como Paulino et al. (2009), que encontraram valores de $1,7 \mathrm{t} \mathrm{ha}^{-1}$ de massa seca para crotalária aos 74 dias do plantio e 2,9 $\mathrm{t} \mathrm{ha}^{-1}$ aos 128 dias de plantio.

A espécie que apresentou a maior produtividade foi $\mathrm{o}$ feijão-de-porco, com biomassa fresca de (Tabela 6), sendo inferior a dados apresentados na literatura, como Wutke et al.

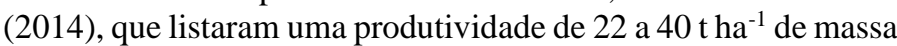
fresca e 5 a $8 \mathrm{t} \mathrm{ha}^{-1}$ para massa seca. A crotalária foi à espécie que apresentou somente $2,1 \mathrm{t} \mathrm{ha}^{-1}$ de massa fresca e $0,99 \mathrm{t} \mathrm{ha}^{-1} \mathrm{de}$ massa seca; para estes mesmos autores, os valores encontrados também foram superiores com 21 a $60 \mathrm{t} \mathrm{ha}^{-1}$ de massa fresca e 4 a $15 \mathrm{t} \mathrm{ha}^{-1}$ de massa seca. Estes resultados demonstraram diferença estatística entre as espécies para o peso da massa fresca e massa seca.

Tabela 6. Massa fresca e seca (média e desvio padrão) e teor de massa seca da parte aérea do feijão-de-porco e crotalária, aos dois meses de plantio, em Santarém, Pará.

\begin{tabular}{|c|c|c|c|c|c|}
\hline \multirow{2}{*}{ Espécie } & \multicolumn{2}{|c|}{ Massa fresca } & \multicolumn{2}{|c|}{ Massa seca } & \multirow{2}{*}{$\begin{array}{c}\text { Teor de massa } \\
\text { seca }(\%)\end{array}$} \\
\hline & $\mathrm{g} /$ planta & t.ha ${ }^{-1 *}$ & $\mathrm{~g} /$ planta & t.ha ${ }^{-1}$ & \\
\hline Feijão de porco & $216,4 \pm 49,4$ & 8,6 & $40,1 \pm 8,7$ & 1,6 & 18,5 \\
\hline Crotalária & $52,8 \pm 12,8$ & 2,1 & $25,0 \pm 8,1$ & 0,99 & 47,3 \\
\hline
\end{tabular}

*Valores considerando o plantio com espaçamento de 50 x $50 \mathrm{~cm}$ entre covas.

Estudo realizado em Goiás (Menezes e Leandro, 2004), constatou que o feijão-de-porco e a crotalária, aos 90 dias após sua emergência, apresentaram produções de fitomassa superiores a 9,0 $\mathrm{t} \mathrm{ha}^{-1}$, resultados próximos ao encontrado no presente estudo para a espécie feijão-de- porco.

Estudo realizado por Dourado et al. (2001) no Mato Grosso do Sul, com desenvolvimento de crotalária aos dois meses sobre ação de diferentes doses de fósforo, encontrou resultados de massa verde que variou de $25,1 \mathrm{t} \mathrm{ha}^{-1}$ a $26,4 \mathrm{t} \mathrm{ha}^{-1}$ e massa seca variando de $3,4 \mathrm{t} \mathrm{ha}^{-1} \mathrm{e} 4,05 \mathrm{t} \mathrm{ha}^{-1}$.

\section{CONCLUSÕES}

Para indicação no uso como adubação verde, a espécie perene gliricídia, apresentou os melhores parâmetros dendrometricos e, a espécie herbácea feijão de porco, a maior produção de biomassa.

$\mathrm{O}$ crescimento inicial demonstrou que a gliricidia é uma espécie com potencial e rusticidade para uso na adubação verde, destacando-se em altura total e diâmetro a altura do colo, em relação ao ingá-xixica.

O feijão de porco se destacou em relação à crotalária, para o desenvolvimento de biomassa, mostrando ser a melhor opção para adubação verde para plantas de ciclo curto.

\section{REFERÊNCIAS}

AGUIAR JÚNIOR, R. A.; SILVA, A. G. P.; BARBOSA, E. C.; ARAÚJO, J. R. G. Relação entre produção de biomassa e biometria de Gliricídia (Gliricidia sepium (Jacq.). Cadernos de Agroecologia, v.6, n.2, p.1-5, 2011.

ALMEIDA, R. O. P. O.; SÁNCHEZ, L. E. Revegetação de áreas de mineração: critérios de monitoramento e avaliação do desempenho. Revista Árvore, Viçosa-MG, v.29, n.1, p.47-54, 2005.
BARRETO, A. C.; CARVAlHO FILHO, O. M. Cultivo de leucena em consórcio com feijão, milho e algodão. Pesquisa Agropecuária Brasileira, Brasília, v.27, n.11, p.1533-1540, 1992.

BENINCASA, M. M. P. Análise de Crescimento de Plantas (noções básicas). Jaboticabal: FUNEP. 2004. 42p.

CARVALHO FILHO, O. M.; DRUMOND, M. A.; LANGUIDEY, P. H. Gliricidia sepium leguminosa promissora para regiões semiáridas. Petrolina: Embrapa/CPATSA, 1997.

CARVALHO, A. M.; BURLE, M. L.; PEREIRA, J.; SILVA, M. A. Manejo de adubos verdes no Cerrado. Planaltina: Embrapa Cerrados, 1999. 28p. (Circular Técnica, 4).

CAVAlCANTE, A. C. P.; CAVALCANTE, A. G.; DA SILVA, M. J. R.; ARAÚJO, R. C. Produção de mudas de gliricídia com diferentes substratos orgânicos. Agrarian, v.9, n.33, p.233-240, 2016.

COSTA, J. R.; CASTRO, A. B. C.; WANDELli, E. V.; CORAL, S. C. T.; SOUSA, S. A. G. Aspectos silviculturais da castanha-do-brasil (Bertholletia excelsa) em sistemas agroflorestais na Amazônia Central. Acta Amazônica, Manaus, v.39, n.4, p.843-850, 2009.

CRAVO, M. S.; VIÉGAS, I. J. M.; BRASIL, E. C. Recomendações de adubação e calagem para o Estado do Pará. 1.ed. Belém: Embrapa Amazônia Oriental, 2010. 44p.

DANCEY, C. P.; REIDY, J. Estatística sem matemática para psicologia. Porto Alegre: Artmed, 2006.

DOURADO, M. C.; DA SILVA, T. R. B.; BOLONHEZI, A. C. Matéria seca e produção de grãos de Crotalaria juncea L. 
submetida à poda e adubação fosfatada. Scientia Agricola, v.58, n.2, p.287-293, 2001.

DRUMOND, M. A.; CARVALHO FILHO, O. M. Introdução e avaliação da Gliricidia sepium na região semi-árida do Nordeste Brasileiro. In: QUEIROZ, M. A de; GOEDERT, C. O.; RAMOS, S. R. R. (Ed.). Recursos genéticos e melhoramento de plantas para o Nordeste brasileiro. Petrolina: Embrapa Semi-Árido; Brasília, DF: Embrapa Recursos Genéticos e Biotecnologia, p.1$8,1999$.

EIRAS, P. P.; COELHO, F. C. Utilização de leguminosas na adubação verde para a cultura de milho. Revista Científica Internacional, v.28, n.4, p. 96-124, 2011.

ESPINDOLA, J. A. A.; GUERRA, J. G. M.; DE-POLLI, H.; ALMEIDA, D. L.; ABBOUD, A. C. S. Adubação verde com leguminosas. 1.ed. Brasília, DF: Embrapa Informação Tecnológica, 2005.

ESPINDOLA, J. A. A.; GUERRA, J.G. M.; PERIN, A.; TEIXEIRA, M. G.; ALMEIDA, D. L.; URQUIAGA, S.; BUSQUET, R. N. B. Bananeiras consorciadas com leguminosas herbáceas perenes utilizadas como coberturas vivas. Pesquisa Agropecuária Brasileira, v.41, p.415-420, 2006.

FARIAS, S. G. G.; SANTOS, D. R.; FREIRE, A. L. O.; SILVA, R. B. Estresse salino no crescimento inicial e nutrição mineral de Gliricídia (Gliricidia Sepium (Jacq.) Kunth Ex Steud) em solução Nutritiva. Revista Brasileira de Ciência do Solo, v.33, n.5, p.1499-1505, 2009.

FERREIRA, J. D. Análise do plano processo na urbanização de cidades no Baixo Amazonas: o caso de Santarém - Brasil. 2011. 118 f. Dissertação (Mestrado em Desenvolvimento e Meio Ambiente Urbano) - Universidade da Amazônia, Belém. 2011.

IDESP. Estatísticas Municipal de Santarém. 2014. Disponível em: <http://www.idesp'pa.gov.br/pdf/statisticaMunicipal>. Acesso em: 14 abr. 2018.

LIMA, J. F.; PEIXOTO, C. P.; LEDO, C. A. S. Índices Fisiológicos e crescimento inicial de mamoeiro (Carica papaya L.) em casa de vegetação. Ciência e Agrotecnologia, Lavras, v.31, n.5, p.1358-1363, 2007.

MACHADO, A. F. L.; FERREIRA, L. R.; FERREIRA, F. A.; FIALHO, C. M. T.; TUFFI SANTOS, L. D.; MACHADO, M. S., 2006. Análise de crescimento de Digitaria insularis. Planta Daninha, v.24, n.4, p.641-647, 2006.

MARIN, A. M. P; MENEZES R. S. C.; SALCEDO, I. H. Produtividade de milho isolado ou em aléias de gliricídia e adubado com duas fontes orgânicas. Pesquisa Agropecuária Brasileira, Brasília, v.42, n.5 p.669-677, 2007.

MATTEI, V. L.; ROSENTHAL, M. D. Semeadura direta de canafístula (Peltophorum dubium (Spreng.) Taub.) no enriquecimento de capoeiras. Revista Árvore, Viçosa-MG, v.26, n.6, p.649-654, 2002.

MATTAR, E. P. L.; DE MORAES, M. D.; FRADE JUNIOR, E. F.; ALÉCIO, M. R.; ORTEGA, G. P. Sistema de Cultivo em aléias-Manual Tecnico, 2013.

MEIRELLES, A. C.; SOUZA, L. A. G. Produção e qualidade da biomassa de leguminosas arbóreas cultivadas em um sistema de aleias em solo Latossolo Amarelo da Amazônia Central. Revista Brasileira de Agroecologia, v. 10, n. 2, 2015.

MENEZES, L. A. S.; LEANDRO, W. M. Avaliação de espécies de coberturas do solo com potencial de uso em sistema de plantio direto. Pesquisa Agropecuária Tropical, v.34, p.173-180, 2004.

MIRANDA, E. M.; VALENTIM, J. F. Desempenho de doze espécies arbóreas nativas e introduzidas com potencial de uso múltiplo no estado do Acre, Brasil. Acta Amazônica, v.30, n.3, p.471-480, 2000.

NASCIMENTO, D. F.; LELES, P. S. S.; OLIVEIRA NETO, S. N.; MOREIRA, R. T. S.; ALONSO, J M. Crescimento inicial de seis espécies florestais em diferentes espaçamentos. Cerne, Lavras, v.18, n.1, p.159-165, 2012.

OLIVEIRA, M. A.; PEREIRA, O. G.; GOMIDE, J. A.; HUAMAN, C. A. M. Y.; GARCIA, R.; CECON, P. R. Análise de crescimento do capim-bermuda 'Tifton 85'(Cynodon spp.). Rev. bras. Zootec., v.29, n.6, p.1930-1938, 2000.

PAULINO, G. M.; ALVES, B. J. R.; BARROSO, D. G.; URQUIAGA, S.; ESPINDOLA, J. A. A. Fixação biológica e transferência de nitrogênio por leguminosas em pomar orgânico de mangueira e gravioleira. Pesquisa Agropecuária Brasileira, Brasília, v.44, n.12, p.1598-1607, 2009.

PAULINO, G. M.; BARROSO, D. G.; LAMÔNICA, K. R.; COSTA, G. S.; ARAÚJO CARNEIRO, J.G. Desempenho da gliricídia no cultivo em aleias em pomar orgânico de mangueira e gravioleira. Revista Árvore, v.35, n.4, p.781-789, 2011.

QUEIROZ, L. R.; COELHO, F. C.; BARROSO, D. G. Cultivo de milho no sistema de aléias com leguminosas perenes. Ciência e Agrotecnologia, v.31, n.5, p.1303-1309, 2007.

SILVA, E. C.; AMBROSANO, E. J.; SCIVITTARO, W. B. Adubação verde como fonte de nutrientes às culturas. In: Adubação verde e plantas de cobertura no Brasil: fundamentos e prática [S.1: s.n.], 2014

SILVA, E. D. Avaliação da parte aérea de mudas de Gliricidia sepium produzidas sob uma perspectiva agroecológica. Revista Brasileira de Agroecologia, v.4, n.2, p.4327-4331, 2009.

SILVA, L. C. R.; CORRÊA, R. S. Sobrevivência e crescimento de seis espécies arbóreas submetidas a quatro tratamentos em área minerada no cerrado. Revista Árvore, v.32, n.4, p.731-740, 2008. 
SILVA, L. F.; MENDONÇA, J. R. Comportamento da gliricídia (G. sepium) em solos de tabuleiro do Sul da Bahia. Ilhéus: Ceplac/Centro de Pesquisa do Cacau, 1995.

SOUSA, S. G. A.; WANDELLI, E. V.; COSTA, J. R.; PERIN, R.; FERNANDES, E. E. C. Potencialidades do ingazeiro (Inga edulis Mart.) e da gliricídia (Gliricida sepium (Jacq.) Kunth ex Walp.) como adubos verdes em agroecossistemas. In: Reunião Amazônica de Agroecologia, 1, 2007, Manaus. A agroecologia no contexto amazônico. [Manaus: Embrapa Amazônia Ocidental, 2007]. p.390-392.

WOLSCHICK, N. H.; BARBOSA, F. T.; BERTOL, I.; SANTOS, K. F.; SOUZA, W. R.; BAGIO, B. (Cobertura do solo, produção de biomassa e acúmulo de nutrientes por plantas de cobertura. Revista de Ciências Agroveterinárias, 2016 p. 134143.

WUTKE, E. B.; CALEGARI; A.; WILDNER, L. Espécies de adubos verdes e plantas de cobertura e recomendações para seu uso. In: LIMA FILHO, O. F.; AMBROSANO, E. J.; ROSSI, F. CARLOS, J. A. D. (Org.). Adubação verde e plantas de cobertura no Brasil. Fundamento e Práticas - Volume I, Brasília: EMBRAPA, 2014. Cap.3, p.59-168.

XISTO, G. J. Potencialidades dos Recursos Naturais da Várzea para Adubação Orgânica na Agricultura em Comunidades Tradicionais na Região do Paraná de Parintins-AM. Revista Brasileira de Agroecologia, v.4, n.2, 2009. 